\title{
Notas de AQUí Y DE ALLÁ
}

\section{- INTERNACIONALES}

- Respondiendo a la quinta convocatoria de Movilidad Internacional para Docentes, otorgada por Resolución de Rectoría No. 01153, pasantías de investigación, la profesora Dora Piñeres De la Ossa, es seleccionada en Purdue University, Indianápolis, Estados Unidos, del 15 de agosto al 15 de octubre de 2016, para realizar pasantía en el Ackerman Center For Democratic Citizenship.

- Congreso Internacional de Educación y Evaluación, desarrollado en la Universidad de Tlaxcala México, "La pedagogía social y la educación social, como una estrategia de formación para la construcción de ciudadanía global en el medio universitario", ponencia presentada por las docentes Rina De León Herrera y Gloria Giammaría de Osorio, del 29 de septiembre al 1 de octubre del 2016.

- X Conferencia Internacional de Estudios Caribeños; Mesa Redonda Especial "Cambio climático, ambiente, educación y desarrollo sostenible en el Caribe". Desarrollado en La Habana, Cuba, "Cambio climático, medio ambiente y desarrollo local en Cartagena (Colombia)", ponencia presentada por el docente Edilbert Torreglosa del 6 al 8 de diciembre de 2016.

- V Seminario Regional Andino, desarrollado en La Paz, Bolivia, "El habitante de calle como sujeto de política social", ponencia presentada por las docentes Kenia Victoria Cogollo y Lidys Agámez González, del 22 al 24 de febrero de 2017.

- Misión Académica Internacional Cooperación Internacional DDHH y Paz, desarrollado en Washington D. C. y New York, Estados Unidos, "Gestión de proyectos sociales para la garantía de los derechos humanos y la paz", ponencia presentada por la docente Lidys Agámez González, del 27 de febrero al 10 de marzo de 2017.

- Seminario Internacional Maestría en Trabajo Social, desarrollado en Paraná, Argentina, "Conflicto armado, desplazamiento y convivencia social: contradicciones, retos", ponencia presentada por la docente Kenia Victoria Cogollo, del 15 al 19 de mayo de 2017. 
- Trabajo Social con Comunidades en Tiempo de Multiculturalidad, desarrollado en Portoviejo, Ecuador, "Retos de la intervención en trabajo social desde una perspectiva intercultural", ponencia presentada por el docente Alexander Pérez Álvarez, del 8 al 16 de agosto de 2017.

\section{NACIONALES}

- I Encuentro Internacional de Estudios de Paz, desarrollado en Valledupar, Colombia, "La cartografía social, una herramienta para reivindicar la historia: apuesta para la construcción de una paz territorial", ponencia presentada por las docentes Marelis Castillo De la Torre y Amelia Segrera López, del 7 al 9 septiembre de 2016.

- II Encuentro Internacional de Grupos de Investigación UNIMAR 50 Años, desarrollado en San Juan de Pasto, Nariño, "Análisis de categorías socioeconómicas para caracterizar la movilidad de desarrollo por ingresos derivados del uso del patrimonio material en Cartagena", ponencia presentada por la docente Lidys Agámez González, del 21 al 24 de septiembre de 2016.

- $3^{\circ}$ Simposio Internacional y $4^{\circ}$ Coloquio Regional de Investigación Educativa y Pedagógica, desarrollado en la Universidad de Córdoba Montería, "Educación ciudadana para el fortalecimiento de la democracia", ponencia presentada por la docente Zohamy Ardila Ramos, del 5 al 7 de octubre de 2016.

- II Seminario Internacional de Trabajo Social, desarrollado en la Universidad Simón Bolívar Barranquilla, "Intervención social para la paz: Diálogo de saberes, territorios e iniciativas de Trabajo Social", ponencia presentada por la docente Lidys Agámez González, el 28 y 29 de octubre de 2016.

- Transformaciones Democráticas, Justicia Social y Procesos de Construcción de Paz, desarrollado en Manizales, Caldas: "Estrategia de construcción de paz de los jóvenes vinculados a barras bravas en el contexto barrial en República de Chile, ciudad de Cartagena", ponencia presentada por la docente Lidys Agámez González, del 7 al 11 de noviembre del año 2016. 
- I Simposio Internacional Educación, Ciencia, Tecnología e Innovación RIDECTEI, desarrollado en Santa Marta Colombia, "Representaciones sociales sobre universidad pública de estudiantes del Centro Tutorial San Juan Nepomuceno de la Universidad de Cartagena", ponencia presentada por la docente Zohamy Ardila Ramos, del 9 al 11 de mayo de 2017.

- I Encuentro Regional de "Educación para la Ciudadanía y el Protagonismo Juvenil en el Proceso de Construcción de Paz", desarrollado por la Institución Tecnológica Colegio Mayor de Bolívar y la Universidad de Cartagena, ¿Asistencialismo o Solidaridad?, ponencia presentada por la docente Gloria Giammaría de Osorio, el 18 y 19 de mayo de 2017.

- II Simposio Iberoamericano de Pedagogía Social en Colombia: la Educación Social, Retos para la Transformación Socioeducativa y para la Paz, desarrollado en la Universidad del Norte, Barranquilla, "Pedagogía social, elementos fundamentales para el trabajo con jóvenes", ponencia presentada por las docentes Gloria Giammaría de Osorio y Rina De León Herrera, el 12 y 13 de junio de 2017. 

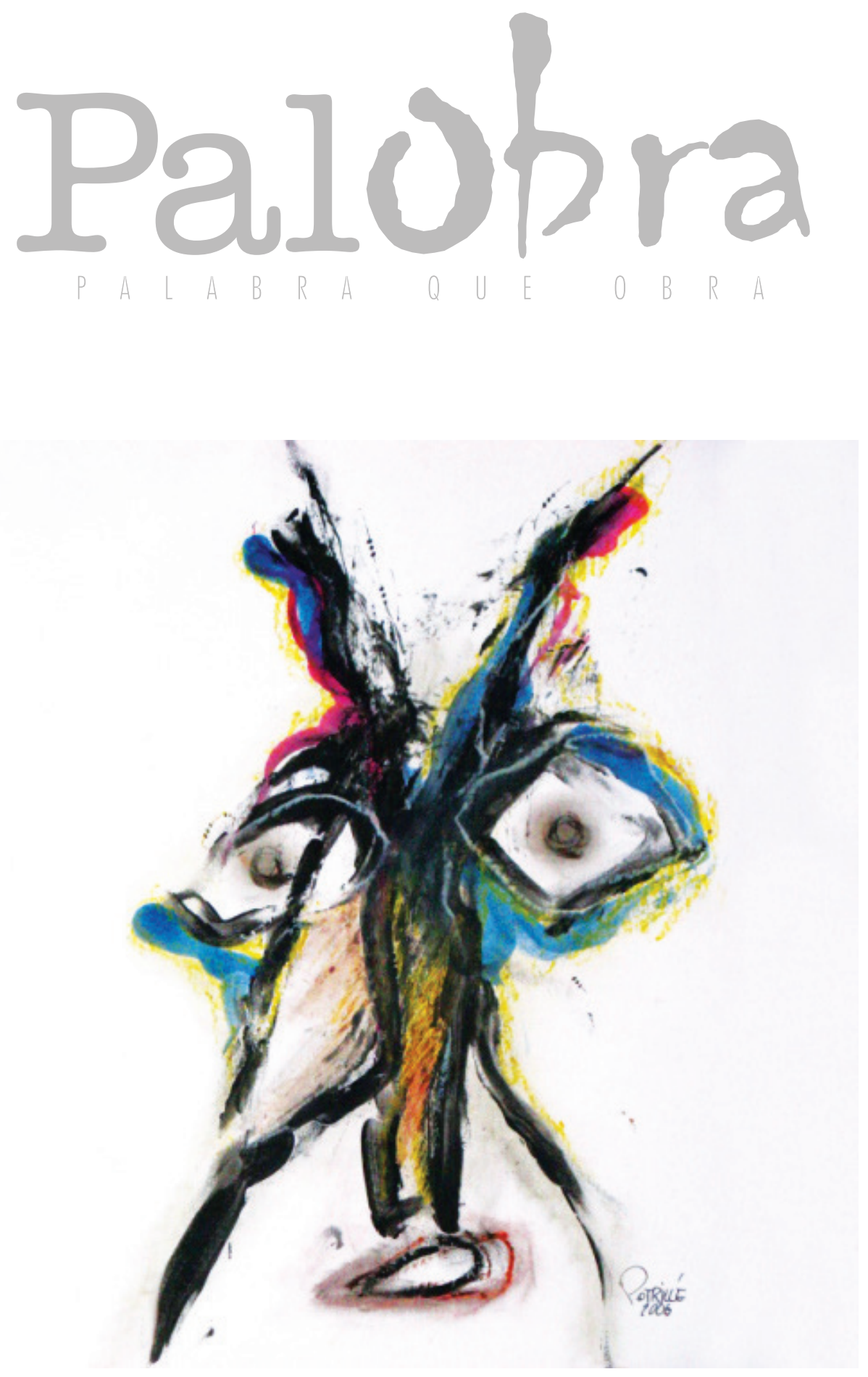

Obra pictórica de la serie "Rostros" de Eduardo Potrillé 